2018 Global Marketing Conference at Tokyo Proceedings: 1109-1113 (July 2018) https://doi.org/10.15444/GMC2018.09.05.03

\title{
EXPLORING HOW BRANDS CREATE AND MAINTAIN ONLINE RELATIONSHIPS THROUGH THEIR WEBSITES, FACEBOOK AND INSTAGRAM BRAND PAGES
}

\author{
Luisa Pinto, Instituto Universitário de Lisboa (ISCTE-IUL), Portugal ${ }^{1}$ \\ Sandra Maria Correia Loureiro, Instituto Universitário de Lisboa (ISCTE-IUL), \\ Portugal $^{2}$ \\ Paulo Rita, Instituto Universitário de Lisboa (ISCTE-IUL), Portugal ${ }^{3}$ \\ Eduardo Moraes Sarmento, University Lusófona, Portugal ${ }^{4}$
}

\begin{abstract}
\section{Introduction}

In the context of online interactions, social media has becoming a crucial part of people's everyday lives, where they converge to exchange, debate, communicate and participate in any form of social interaction (Ryan \& Jones, 2009). They post and share new content but also review and rate products/services and/or brands, share experiences and expertise and exchange opinions (Ryan \& Jones, 2009). As a result, the growing popularity of social media, the competitors' presence on social networking sites and the cost reduction pressure derived from the financial crisis and consequent necessity to find cheaper solutions for brand promotion, motivated companies to use social media as part of their marketing and brand building activities (Tsimonis \& Dimitriadis, 2014) and to create brand fan pages in different social networks such as Facebook, Instagram, Twitter, and YouTube, among others.

Due to this attractiveness, social media is becoming the media channel of choice across the world (Dong-Hun, 2010). However, traditional media still plays an important role for both consumers and marketers, being a central component of brands' communication strategies. Yet, several questions still remain unanswered regarding social media effectiveness and influence on consumer engagement. In the current study we intend that we intend to contribute to fulfil the second. Thus, the objective of the current study is to explore how brands create and maintain online relationships with consumers through their Websites, Facebook and Instagram brand pages
\end{abstract}

\section{Theoretical development}

The concept of engagement was originally employed in different fields of study including psychology, sociology and organizational behaviour. Now is attracting marketers' attention especially in the field of relationship marketing (e.g., Brodie et al., 2011; Hollebeek, 2011). Accordingly, two central concepts consumer engagement and online brand engagement need to be defined. First, consumer engagement, refers to the intensity of a person's participation and connection with company's offerings and activities that can be initiated by the consumer or the organization (Vivek, Beatty, \& Morgan, 2012). Online brand engagement, on the other hand, can be defined as a consumer's cognitive and affective commitment to partake in an active relationship

\footnotetext{
${ }^{1}$ luisa.teixeirapinto@gmail.com

2 sandramloureiro@netcabo.pt

${ }^{3}$ paulo.rita@iscte-iul.pt

4 emoraessarmento@gmail.com
} 
with a brand on a website or other computer-mediated platform designed to communicate brand value (Mollen \& Wilson, 2010). Online brand engagement measures how much and how frequently users interact with a firm's page and its social media content. When consumers make the effort to like, favourite or comment a brand's post, they are vigorously engaging with that content. Engagement metrics display audience action, an important feature for social media health and growth (Dunham, 2014).

As social media provides numerous ways for users to get involved with organizations (Waters, Burnett, Lamm, \& Lucas, 2009), marketers must find rightful strategies to nurture relationships with the public. Dialogue has been one of the topics under research by several scholars. Including this two-way form of communication is crucial to "understand how organizations can build relationships that serve both organizational and public interests" (Kent \& Taylor, 2002: 21), thus several studies use dialogic communication to investigate the influence of online strategies for relationship building (Loureiro \& Gomes, 2016). Three crucial strategies have been used in numerous studies (Waters et al., 2009; Loureiro \& Gomes, 2016; Men \& Tsai, 2012) to build and maintain relationships online: disclosure or openness, information dissemination, and interactivity and involvement.

First, disclosure or openness refers to the companies' willingness to be transparent in their online communication activities. Waters et al. (2009) suggest that companies must provide information such as company's full description, its history and mission. Organizations should use hyperlinks connected to their websites and use logos and visual cues to enhance brand recognition. Information dissemination concerns posting photos and videos, announcements about products, as well as answering questions to address stakeholders' needs, concerns and interests (Men \& Tsai, 2012; Loureiro \& Gomes, 2016). Posting links to external news content related to the company and its business and including press releases and campaign summaries can maximize the impact of a company's online presence (Waters et al., 2009). Finally, interactivity and involvement can be seen as the most important strategy, out of the three, since it is essential to foster relationships with the public and represents one of the main advantages of using different social media platforms (Haigh, 2014). This strategy is often analysed as a whole, with no distinction between the two terms (Men \& Tsai, 2012; Loureiro \& Gomes, 2016) however, interactivity can be analysed separately from involvement according to research done by Haigh (2014).

Involvement regards connecting with consumers. Providing information such as organizational contacts, giving users the ability to stay in touch with the company is one way to involve them. Interactivity, on the other hand, is often defined as "the extent to which users can participate in modifying the form and content of the mediated environment in real time." (Steuer, 1992: 84). When considering computermediated environments, Liu (2003) also studied interactivity, developing a scale to measure interactivity on websites. According to the study, interactivity should be defined as "the degree to which two or more communication parties can act on each other, on the communication medium, and on the messages and the degree to which such influences are synchronized" (Liu \& Shrum, 2002: 54) and three dimensions should be included when discussing this topic: active control, two-way communication and synchronicity. Active control regards users' capacity to voluntarily participate and usefully influence communications. Two-way communication concerns the bifacial flow of information. Synchronicity evaluates the speed of the interaction. This led to the definition of interactive communication: 
"communication that offers individuals active control and allows them to communicate both reciprocally and synchronously" (Liu, 2003: 208).

Finally, human-to-content interactivity refers to the ability to contribute to the organizational online content by commenting on organizational posts and to reply to other users' posts. (Loureiro \& Gomes, 2016; Men \& Tsai, 2012). Thus, considering the above-mentioned, the following research question is proposed:

RQ1: What strategies are Portuguese companies incorporating to create and maintain relationships with publics on their Websites, Facebook and Instagram pages?

\section{Research design}

We conducted an exploratory content analysis to investigate online relationship cultivation strategies by Portuguese brands (RQ1). Following Loureiro and Gomes (2016), first we retrieve a list of the 50 most valuable Portuguese brands of 2016 provided by Brand Finance, “...the world's leading independent branded business valuation..." (The Brand Finance Group, 2016). This list is made with regards to the brand value (USD \$ millions) and the brand rating in the year under analysis, therefore raking the top 50 Portuguese brands. Afterwards, from this initial sample of 50 companies, brands are analysed in terms of their presence in social media by verifying if they have an official website and brand fan Pages on Facebook Instagram. After examining their social media presence, the sample included 47 companies with a website, 28 companies with a Facebook page and 19 with an Instagram account. Pages without information or not maintained by the organisation were not considered. Coding categories used in this analysis are adapted from previous research (Waters et al., 2009; Men \& Tsai, 2012; Haigh, 2014; Loureiro \& Gomes, 2016). The categories coded are the same for Website, Facebook and Instagram pages. Based on Waters et al.'s (2009) method for coding online relationship cultivation strategies, the website and social media pages are examined to identify the presence of items representing organizations' strategies of disclosure, information dissemination and involvement.

The units of analysis are the website corporate profile page on Facebook and Instagram page. We evaluate whether each strategy and item occurred, hence categories are coded with 'yes' or 'no' depending if the information was present (Haigh, 2014). On websites, the first step is to go to the homepage and see if the website provided a site map to easily find the items belonging to each strategy. When site maps are not available, each tab inside the website would be inspected to look for the information needed for each strategy. Since websites are more complex, with information spread across them instead of reunited in one single page as in Facebook and Instagram the following analyses were simpler. On Facebook the first page of each corporate profile is studied. This is the page that users see after signing in and where they have access to all the main elements, including the photo album and the message board. The details examined on each page are items that are readily observable (Men \& Tsai, 2012). On Instagram, the analysis is similar to Facebook. Here, most of the page is visually-based (photos and videos) with the exception of to the brief description below the profile picture or logo (where usually companies also insert the URL to the Website). Thus, we look to photos' descriptions to get more insights about the content shared and the cultivation strategies implemented. Users' comments are also considered to evaluate, whether or not companies reply to them and initiate conversations with consumers. Intercoder reliability was tested using Perreault \& Leigh's (1989) formula. 


\section{Main results and conclusions}

Websites perform better in the first two strategies (disclosure and information dissemination) by frequently displaying a brief description about the business as well as brand history, logo and visual cues, news links and information about achievements and awards. However, in what concerns the last strategy, interactivity and involvement, websites lack interactive features that allow firms to engage with consumers such as commenting and sharing opportunity. Generally, actions to foment online participation are not implemented. This could be explained by the fact that Websites' main purpose is, according to Keller (2009), to express ambitions, history, products as well as the firms' vision therefore they act more as sources of information than as sources of interaction. However they still have to be attractive enough to encourage repeated visits (Keller, 2009).

By contract, brand fan pages on Facebook and Instagram disclose and disseminate less information about firms and their activities (more evident on Instagram) and perform better in the interactivity and involvement strategy. In accordance with (Jahn \& Kunz, 2012), brand fan pages main goal is to promote a communicative and interactive channel that creates a bond between the user and the brand, therefore it is expected that the main strategy used to nurture relationships on these social networks is the one that enables interaction and encourages involvement.

Finally, comparing the three SNS's, Facebook seems to be the more consistent channel to combine and implement the three strategies altogether, since it displays a better overall performance. However, each social networking site has its own role, therefore companies should consider which network works best for each strategy and for each type of consumer and build an overall plan that maximizes the potential to connect with consumers, remembering that the image they build online should present an accurate representation of the brand and should align with other marketing efforts to present consistent messages to customers.

Regarding consumer engagement, brands should focus on creating interesting and captivating content instead of posting too regularly just to have an active online presence. Posting more often does not necessarily lead to online brand engagement. Moreover, having more followers is not necessarily good on its own. Fans need to feel connected to the brand and its content and usually, smaller audiences are more engaged with brands. Therefore, brands should work on strategies that allow them to grow their audience while keeping the perks of interacting with smaller audiences. Also, audience growth rate is a helpful measure to evaluate performance on each network, identify which one is generating the highest rates and investigate how to gain more followers on all networks. Additionally, it may be useful in tracking specific campaigns' success.

Keywords: online relationships, websites, Facebook, Instagram, social media

\section{References (more upon request)}

Brodie, R. J., Hollebeek, L. D., Juric, B., \& Ilic, A. (2011). Customer Engagement : Conceptual Domain, Fundamental Propositions, and Implications for Research. Journal of Service Research, 14(3), 252-271.

Dong-Hun, L. (2010). Growing popularity of social media and business strategy . SERI Quartely, 3(4), 112-117.

Dunham. (2014, May 27). The beginner's guide to social media metrics: Engagement. Retrieved from Hootsuite: https://blog.hootsuite.com/beginners-guideengagement/ 
Haigh, M. M. (2014). Comparing how organisations use websites and social media to maintain organisation-public relationships. Obtido de PRism: http://www.prismjournal.org/fileadmin/11_2/Haigh.pdf

Hollebeek, L. (2011). Exploring customer brand engagement: definition and themes. Journal of Strategic Marketing, 19 (7), 555-573.

Liu, Y. (2003). Developing a scale to measure the interactivity of websites. Journal of advertising research, 43(2), 207-216.

Liu, Y., \& Shrum, L. J. (2002). What is interactivity and is it always such a good thing? Implications of definition, person, and situation for the influence of interactivity on advertising effectiveness. Journal of Advertising, 31(4), 53-64.

Loureiro, S., \& Gomes, D. (2016). Relationship between companies and the public on facebook: The Portuguese and the Brazilian context. Journal of Promotion Management, 22(5), 705-718.

Men, L. J., \& Tsai, W. S. (2012). How companies cultivate relationships with publics on social network sites: Evidence from China and the United States. Public Relations Review, 38, 723-730.

Mollen, A., \& Wilson, H. (2010). Engagement, telepresence and interactivity in online consumer experience: Reconciling scholastic and managerial perspectives. Journal of Business Research, 63(9/10), 919-925.

Ryan, D., \& Jones, C. (2009). Understanding digital marketing; Marketing strategies for engaging the digital generation. London and Philadelphia: Kogan Page.

Steuer, J. (1992). Defining virtual reality: dimensions determining telepresence. Journal of Communication, 42(4), 73-93.

Tsimonis, G., \& Dimitriadis, S. (2014). Brand strategies in social media. Marketing Intelligence \& Planning, 32(3), 328-344.

Vivek, S. D., Beatty, S. E., \& Morgan, R. M. (2012). Customer engagement: Exploring customer relationships beyond purchase. Journal of Marketing Theory and Practice, 20(2), 127-145.

Waters, R., Burnett, E., Lamm, A., \& Lucas, J. (2009). Engaging stakeholders through social networking: How nonprofit organizations are using Facebook. Public Relations Review, 35, 102-106. 